\title{
Synthesis of mesoporous cerium compound for $\mathrm{CO}_{2}$ capture
}

\author{
Guiqing Liu ${ }^{1, *}$, Kou Tatsuda $^{2}$, Yoshiharu Yoneyama ${ }^{1}$, and Noritatsu Tsubaki ${ }^{1}$ \\ ${ }^{1}$ University of Toyama, Faculty of Engineering, Gofuku 3190, Toyama-shi, Toyama 930-8555, Japan \\ ${ }^{2}$ JGC Plant Innovation Co., Ltd, 1-13-1, Saido, Kounan-ku, Yokohama, Kanagawa Prefecture
}

\begin{abstract}
A mesoporous adsorbent was simply synthesized by adding alkaline substances to cerium(III) nitric hydrate. The surface characteristics of the synthesized cerium compound were determined with $\mathrm{BET}, \mathrm{XRD}$ and TEM analysis. It was found that although the specific surface areas of the synthesized cerium compounds were among about $120-200 \mathrm{~m}^{2}$ per gram (BET area) which were smaller than the common used zeolite 13X (BET area $743 \mathrm{~m}^{2} / \mathrm{g}$ ) and activated carbon (BET area $1079 \mathrm{~m}^{2} / \mathrm{g}$ ), but the cerium compounds had excellent performances for $\mathrm{CO}_{2}$ adsorption as well as the $\mathrm{CO}_{2}$ desorption.
\end{abstract}

\section{Introduction}

Many investigations have shown that carbon dioxide $\left(\mathrm{CO}_{2}\right)$ emissions are responsible for climate change. So many advanced countries have promoted the reduction of $\mathrm{CO}_{2}$ emitted from large stationary sources including coal-based power plants, steel industry plants, biogas plants, and chemical plants. The development of both economical and environmental benign ways to separate and storage the $\mathrm{CO}_{2}$ has become a global challenge. Two major approaches have been implemented as $\mathrm{CO}_{2}$ separation technology: carbon dioxide capture/sequestration (CCS) and sustainable utilization of captured $\mathrm{CO}_{2}$ as a raw material. The latter will play an important role within the next decade because $\mathrm{CO}_{2}$ is a non-toxic, abundant, easily available, and renewable carbon resource that can be converted into various useful chemical products. A state-of-the-art process for capturing $\mathrm{CO}_{2}$ from largely exhausted flue gases has been developed by employing amine-based, regenerative chemical absorption using aqueous amines. This process has a high efficiency for $\mathrm{CO}_{2}$ capture, but it is energy intensive, complex and requires a high-energy input for regenerating and handling the corrosive solvents that result from the oxidation of amine-based solutions.

Compared with the conventional amine-based absorption, a process for capturing $\mathrm{CO}_{2}$ using novel solid adsorbents capable of energy-efficient reversibility is far more advantageous. In this regard, various porous materials with fine structural and chemical properties have been widely investigated including zeolites, activated carbon, aminemodified silica materials, and metal organic frameworks. Those materials have been

\footnotetext{
${ }^{*}$ Corresponding author: liugq@eng.u-toyama.ac.jp
} 
practical candidates that allow us to perform pressure swing adsorption (PSA) and temperature swing adsorption (TSA) processes for $\mathrm{CO}_{2}$ capture from a variety of large emission sources.

Many studies have suggested that synthetic zeolites and amine-modified mesoporous materials could be applicable for $\mathrm{CO}_{2}$ capturing in the post-combustion flue gas with low concentration of $\mathrm{CO}_{2}$ and low pressure region. Chaikittisilp and Jones have reported that amine-modified mesoporous materials were effective for the $\mathrm{CO}_{2}$ capturing from dilute $\mathrm{CO}_{2}$ containing flue gas $(<10 \%)$ under ambient condition [1]. Yu and Cheng succeeded in the fabrication of amine-functional porous silica microspheres, which showed good $\mathrm{CO}_{2}$ adsorption-desorption performance under high temperature flue gas condition (in the range of 348-383 K) with excellent cyclic stability [2]. These novel porous materials may useful under some conditions, though, the conditions of flue gases $\left(\mathrm{CO}_{2}\right.$ concentration, pressure, gas components, etc.) may sensitively limit the range of applications, thereby adsorbents must be selected appropriately according to the target emission sources. For instance, the high pressure gasification process may exhaust high concentration of pre-combustion $\mathrm{CO}_{2}$ gas with an elevated pressure. Capturing the $\mathrm{CO}_{2}$ from high pressure flue gases would profit in terms of energy-efficiency in the PSA process, thus the adsorbents should be suitable to capture sufficient amount of $\mathrm{CO}_{2}$ under high pressure region. Current PSA adsorbents such as zeolites and amine-modified mesoporous materials may not be most suitable materials for capturing high concentration of $\mathrm{CO}_{2}$ under high pressure condition. Activated carbon still shows low durability against water vapour whereas mesoporous carbon materials specially designed for $\mathrm{CO}_{2}$ capture is also high cost.

In this study, we focused on the use of metal oxides with larger true densities than other porous materials, in particular, we considered cerium compounds such as cerium oxide and cerium hydroxide as an alternative, efficient adsorbent for the $\mathrm{CO}_{2}$ capture process. Cerium oxide, known as ceria, has been a subject of thorough investigations, and has attracted a lot of attention mainly in the field of catalysts and catalytic supports [3]. Many attempts have been made to improve the catalytic activity of ceria by enhancing its thermal stability and surface area with ordered porous structures. However, the practical application of ceria to $\mathrm{CO}_{2}$ capture has not been fully investigated even though conventional ceria has the potential to adsorb and desorb the $\mathrm{CO}_{2}$ under ambient conditions owing to its strong ewis-base sites [4].

In order to develop a high efficient cerium compounds adsorbents for capturing $\mathrm{CO}_{2}$, the primary interest is to enhance the surface area of cerium compounds. Several approaches have been proposed for increasing the surface area. These approaches include the soft-templating method using poly-block copolymers or organic structure-directing agents, the hard-templating method, which usually replicates the ordered mesoporous structures from SBA-15, KIT-6 or MCM-48, the self-assembly of surface modified ceria nanoparticles, and supercritical drying under $\mathrm{CO}_{2}$ conditions. The above methods provide ways to enhance the surface area of ceria to around $200 \mathrm{~m}^{2} \mathrm{~g}^{-1}$. However, these processes are complex, high cost and high energy consumption. Therefore, a simple synthesis route is desirable for the production of high surface area ceria from both industrial and environmental standpoints.

In this study, we tried a simple preparation of mesoporous cerium compounds with a high surface area of up to $206 \mathrm{~m}^{2} \mathrm{~g}^{-1}$. The mesoporous ceria was prepared based on the so-gel method, where the product was simply precipitated within a short reaction period at room temperature under optimized synthesis conditions. Compared with the commercially available non-porous ceria, zeolite $13 \mathrm{X}$, and activated carbon, the prepared mesoporous cerium compounds showed the results with high performance of $\mathrm{CO}_{2}$ adsorption-desorption. 


\section{Experiments}

\subsection{Simple synthesis of mesoporous cerium compounds without template}

The following raw materials were used as provided: using sodium hydroxide or ammonia as alkali sources and cerium (III) nitrate 6-hyrate $\left(\mathrm{Ce}\left(\mathrm{NO}_{3}\right)_{3} \cdot 6 \mathrm{H}_{2} \mathrm{O}\right.$, Kanto Chemical Co., Ltd) as the cerium source. To compare the $\mathrm{CO}_{2}$ adsorption capacity of the cerium products, commercially available non-porous ceria, typical activated carbon and zeolite $13 \mathrm{X}$ were used as reference materials.

The mesoporous cerium compound samples were synthesized by the following procedure: cerium (III) nitrate 6-hyrate $\left(\mathrm{Ce}\left(\mathrm{NO}_{3}\right)_{3} \cdot 6 \mathrm{H}_{2} \mathrm{O}\right.$ was added to ethanol $(99.5 \%$ $\mathrm{C}_{2} \mathrm{H}_{5} \mathrm{OH}$, Kanto Chemical Co., Ltd ) and stirred for $2 \mathrm{~h}$ to obtain a colloid (A). $\mathrm{NaOH}$ was mixed with distilled water with various $\mathrm{OH} / \mathrm{H}_{2} \mathrm{O}$ ratios. Then the $\mathrm{NaOH}(\mathrm{B})$ solution was added to the $\mathrm{A}$ and mixed thoroughly using a magnetic stirrer at room temperature until the suspension became faint yellow. The resulting solution was then separated with a centrifugation. The sediment product was washed with distilled water until it approached a neutral $\mathrm{pH}$ and thereafter dried at room temperature in a vacuum desiccator over one night.

\subsection{Characterization}

The wide-angle powder X-ray diffraction (XRD) patterns of the solid products were collected by a powder X-ray diffractometer (Ultima IV, Rigaku Corp.). The crystalline morphology and crystal size of the products were observed using a transmission electron microscope (TEM, H-7650, Hitachi High-Technologies Corp.) with an accelerating voltage of $100 \mathrm{kV}$. The pore characteristics of the samples were evaluated by performing $\mathrm{N}_{2}$ adsorption-desorption measurement using an automatic gas adsorption apparatus (3 Flex, SHIMADZU Corp.). To evaluate the surface areas, the Brunauer-Emmett-Teller (BET) method was applied. The pore size distribution curves were calculated with the Dollimore-Heal (DH) method.

\section{$2.3 \mathrm{CO}_{2}$ capturing experiment}

A simplified schematic diagram of the experimental setup is shown as Figure 1.The experiments were carried out under a pressure of $0.1,0.5,1.0$, and $1.5 \mathrm{MPa}$ respectively, at room temperature. The sample amount was fixed to $3.0 \mathrm{~g}$. Before adsorption operates the system was purged with pure $\mathrm{N}_{2}$ gas for $1 \mathrm{~h}$. The concentrations of $\mathrm{CO}_{2}$ in the input and output were determined by GC/TCD ( GC-8A, SHIMADZU Corp.) The capturing capacities for $\mathrm{CO}_{2}$ were calculated by the following equation.

$$
Q(\mathrm{mmol} / \mathrm{g})=\frac{\frac{V \times 44}{22.4}\left[\int_{0}^{t}\left(C_{0}-C_{t}\right) d t\right]}{m}
$$

where $Q$ is the $\mathrm{CO}_{2}$ capturing capacity, $\mathrm{mmol} / \mathrm{g} ; V$ is the flow rate of the gas, $\mathrm{L} / \mathrm{min} ; m$ is the weight of the adsorbent sample, $\mathrm{g} ; t$ is the adsorption time, min.; $C_{0}$ and $C_{\mathrm{t}}$ is the $\mathrm{CO}_{2}$ concentration in the input and output, respectively. 


\subsection{Adsorbent regeneration performance evaluation}

The best synthesized sample (Sample No. 2) and zeolite 13X were selected to carry out circulating adsorption-desorption experiments to compare their regenerating performance. For each cycle, at first, the adsorption experiment was carried out at $298 \mathrm{~K}$, under 1.0 MPa. When the adsorption reached the saturating point, the pressure in the reactor was released to atmospheric pressure, and then the reactor was purged with pure nitrogen gas for 1 hour to desorb the captured $\mathrm{CO}_{2}$. The adsorption /desorption circulating experiments were carried out 10 cycles for each sample.

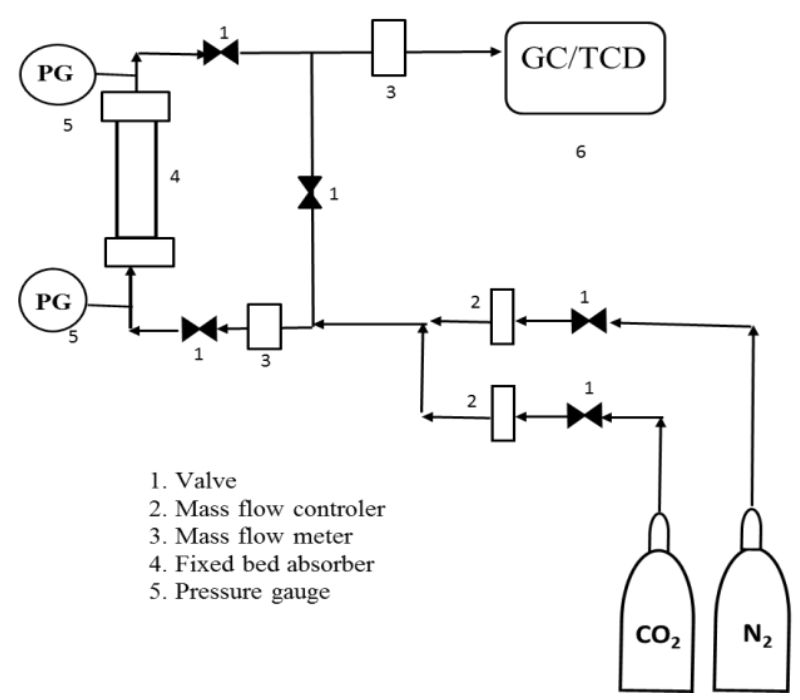

\begin{tabular}{lll}
\hline Temperature & $\mathrm{K}$ & 298 \\
Pressure & $\mathrm{MPa}$ & $0.1,0.5,1.0$ \\
\hline
\end{tabular}

Fig. 1. Fixed-bed adsorption system for $\mathrm{CO}_{2}$ adsorption-desorption experiments.

\section{Results and discussion}

\subsection{Material synthesis and characterization}

\subsubsection{Synthesis of mesoporous cerium compound}

During the stirring, the colour of the precipitate suspension changed from brown to faint yellow as shown in Figure 2. 

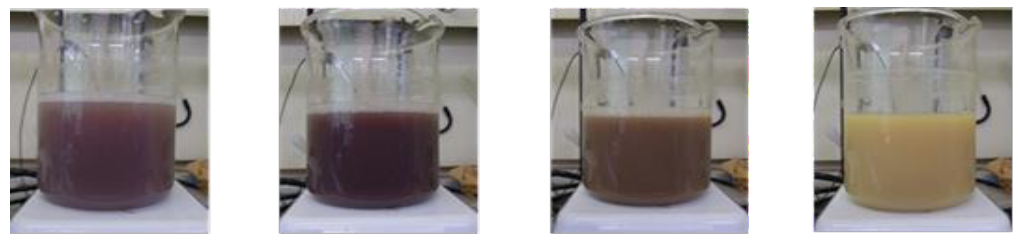

Fig. 2. The color change of the precipitate suspension for the sample with continuous stirring.

The reaction process could be explained as follows: at the initial stage of the reaction, hydrolyzed $\mathrm{Ce}\left(\mathrm{NO}_{3}\right)_{3}$ mixed with $\mathrm{NaOH}$ formed $\mathrm{Ce}(\mathrm{OH})_{3}$

$$
\mathrm{Ce}^{3+}+3 \mathrm{OH}^{-} \rightarrow \mathrm{Ce}(\mathrm{OH})_{3}
$$

here, the color of the aqueous suspension was turned into purple due to the presence of $\mathrm{Ce}(\mathrm{OH})_{3}$ species. When the reaction was further proceeded, the color eventually turned into faint yellow color, and the precipitation of $\mathrm{CeO}_{2}$ obtained. Thus at the latter stage of the reaction, most of $\mathrm{Ce}(\mathrm{OH})_{3}$ formed during hydrolysis-condensation subsequently by the following oxidation step with the oxygen in the air,

$$
4 \mathrm{Ce}(\mathrm{OH})_{3}+\mathrm{O}_{2} \rightarrow 4 \mathrm{CeO}_{2}+6 \mathrm{H}_{2} \mathrm{O}
$$

The mesoporous ceria was synthesized based on sol-gel chemistry at room temperature in highly alkaline solutions with several different $\mathrm{NaOH}$ concentrations (see Table 1).

\begin{tabular}{|c|c|c|c|c|c|}
\hline \multirow[t]{2}{*}{ Sample No. } & \multicolumn{2}{|c|}{ Synthesis condition } & $S_{\text {BET }}\left(\mathrm{m}^{2} \mathrm{~g}^{-1}\right)$ & $P V\left(\mathrm{~cm}^{3} \mathrm{~g}^{-1}\right)$ & $d(\mathrm{~nm})$ \\
\hline & Alkali & $\mathrm{M}\left(\mathrm{mol} \mathrm{L}^{-1}\right)$ & & & \\
\hline 1 & $\mathrm{NaOH}$ & 0.11 & 152 & 0.29 & 5.9 \\
\hline 2 & $\mathrm{NaOH}$ & 0.22 & 206 & 0.21 & 3.0 \\
\hline 3 & $\mathrm{NaOH}$ & 0.28 & 182 & 0.34 & 3.6 \\
\hline 4 & $\mathrm{NaOH}$ & 0.42 & 190 & 0.42 & 4.1 \\
\hline 5 & $\mathrm{NaOH}$ & 0.84 & 191 & 0.41 & 3.7 \\
\hline $\begin{array}{l}6 \text { (calcinated at } \\
873 \mathrm{~K} \text { for } 10 \mathrm{~h} \text { ) }\end{array}$ & $\mathrm{NaOH}$ & 0.22 & 20 & 0.03 & 10.3 \\
\hline
\end{tabular}

Table 1. BET surface area, total pore volume, average crystallite size of the products obtained.

$M$ : mol concentration of aqueous solution ; $S_{\mathrm{BET}}$ : surface area calculated using BET method ; $P V$ : pore volume obtained from the volume of $\mathrm{N}_{2} ; d$ : the average crystallite size evaluated from Scherrer's equation.

Table1 shows that synthesis of the cerium compound by $0.22 \mathrm{M} \mathrm{NaOH}$ solution obtained a sample with highest surface area up to $200 \mathrm{~m}^{2} \mathrm{~g}^{-1}$, and the average crystallite size evaluated by Scherrer's equation was the smallest. The surface area of this sample is excellent comparing with those reported by literature references.

\subsubsection{XRD analysis}

Figure 3 shows the results of wide-angle powder XRD measurements of the synthesized solid products and a commercially available ceria (non-porous ceria). The obtained broad $\mathrm{XRD}$ patterns of the products were identified as pure crystalline ceria with six noticeable 
peaks located at $2 \theta=28.5^{\circ}, 32.6^{\circ}, 47.1^{\circ}, 55.8^{\circ}, 68.7^{\circ}$, and $76.5^{\circ}$, which can be indexed to the (111), (200), (220), (311), (400), and (331) reflections [4], respectively. For the product obtained by $0.22 \mathrm{M} \mathrm{NaOH}$, after it was calcinated at $873 \mathrm{~K}$, the peak intensity greatly enhanced. The crystallite size of the calcinated ceria greatly increased from $3.0 \mathrm{~nm}$ to $10.3 \mathrm{~nm}$ owing to the further crystal growth of ceria induced by the calcination at high temperature.

\subsubsection{TEM morphological features}

The morphological features as well as particle sizes were observed by TEM. The TEM images of three synthesized samples are shown in Fig. 4. It is noticed that synthesized products were clearly agglomerates composited by fine particles. The shapes and sizes of the particles depended upon the concentration of alkaline solution.

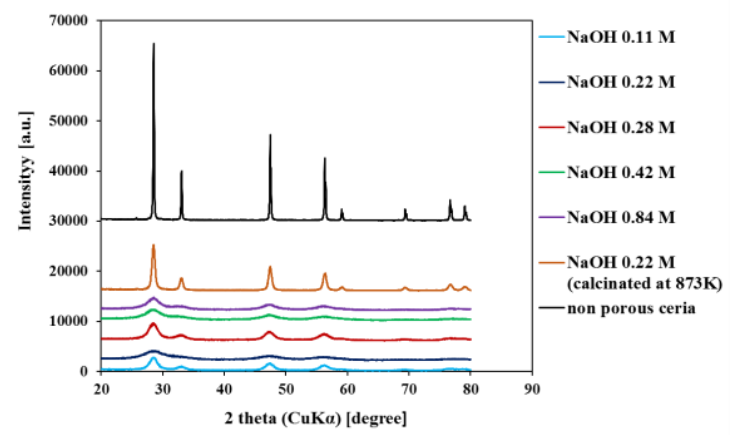

Fig. 3. XRD patterns of ceria synthesized with $\mathrm{NaOH}$.
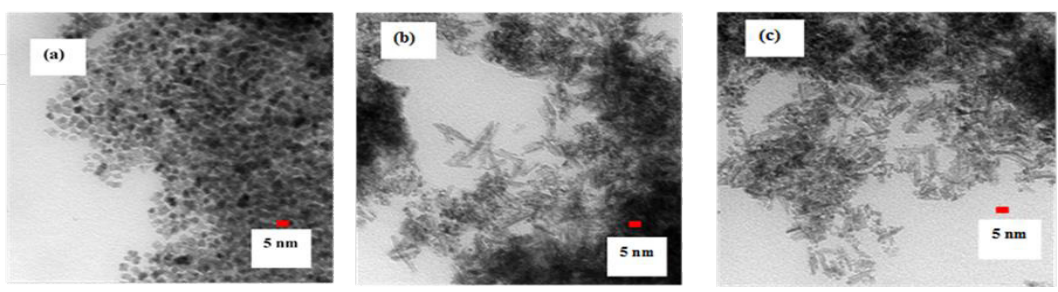

Fig. 4. TEM images of ceria synthesized with $\mathrm{NaOH}$. (a) Sample no.2 (NaOH 0.22 M), (b) Sample no.3 (NaOH 0.42 M), (c) Sample no.4 (NaOH 0.84 M).

\subsubsection{Pore size distribution}

The pore size distributions of the synthesized products were obtained by nitrogen adsorption/desorption isotherms calculated using the Dollimore Heal (DH) method ( see Fig.5). Except the sample obtained by $0.22 \mathrm{M} \mathrm{NaOH}$, which gave a sharp distribution for the pore size, all the samples gave broad distributions for pore size which covered the meso-porous region. 


\section{ASEE17}

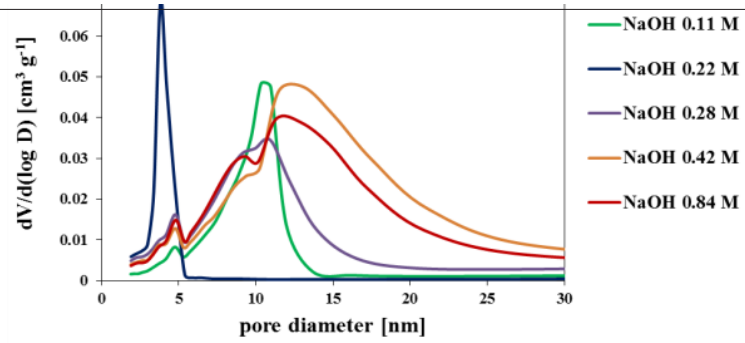

Fig. 5. Pore size distribution of ceria calculated using the Dollimore Heal (DH) method.

\section{$3.2 \mathrm{CO}_{2}$ capture}

\subsection{1 $\mathrm{CO}_{2}$ capturing capacity}

The $\mathrm{CO}_{2}$ capturing capacities of the best synthesized product as well as commercial available adsorbents were compared shown on Fig.6, and their surface areas and pore sizes shown on Table 3. Although the surface area of the synthesized ceria (non-calcinated) is smaller than both the zeolite $13 \mathrm{X}$ and activated carbon, it had more excellent $\mathrm{CO}_{2}$ capturing performance expecially under high pressure.

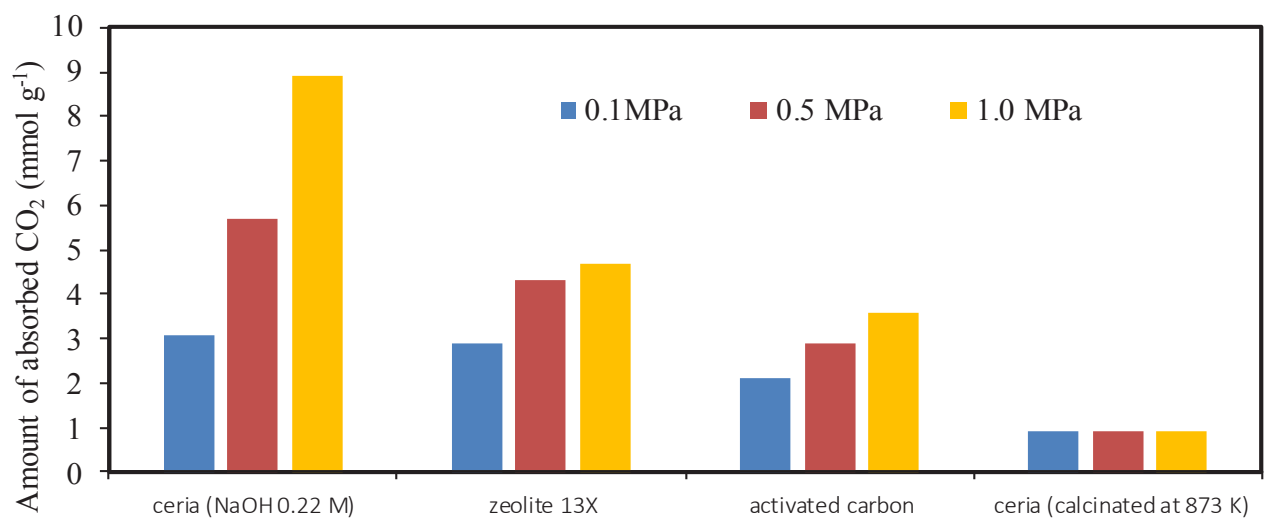

Fig. 6. Capturing capacities of adsorbents for $\mathrm{CO}_{2}(298 \mathrm{~K}, 0.1 \mathrm{MPa}$, $0.5 \mathrm{MPa}, 1.0 \mathrm{MPa}$ ).

Table 3. Compare of amount of $\mathrm{CO}_{2}$ capturing capacities among the different adsorbents.

\begin{tabular}{|c|c|c|c|c|c|}
\hline \multirow{2}{*}{ Sample } & \multirow{2}{*}{$\begin{array}{c}S_{\text {BET }} \\
\left(\mathbf{m}^{2} \mathbf{g}^{-1}\right)\end{array}$} & \multirow{2}{*}{$\begin{array}{c}P D \\
(\mathbf{n m})\end{array}$} & \multicolumn{3}{|c|}{ Amount of adsorbed $\mathrm{CO}_{2}\left(\mathrm{mmol} \mathrm{g}^{-1}\right)$} \\
\hline & & & $0.1 \mathrm{MPa}$ & $0.5 \mathrm{MPa}$ & $1.0 \mathrm{MPa}$ \\
\hline Ceria $(\mathrm{NaOH} 0.22 \mathrm{M})$ & 206 & 3.8 & 3.1 & 5.7 & 8.9 \\
\hline zeolite $13 \mathrm{X}$ & 743 & 1.0 & 2.9 & 4.3 & 4.7 \\
\hline activated carbon & 1079 & 2.9 & 2.1 & 2.9 & 3.6 \\
\hline Ceria (calcinated at $873 \mathrm{~K}$ ) & 20 & 4.0 & 0.9 & 0.9 & 0.9 \\
\hline
\end{tabular}




\subsubsection{Regeneration}

Circulating adsorption-desorption experiments were carried out using the synthesized cerium product (sample No. 2) and comparing with the zeolite $13 \mathrm{X}$. The results of $\mathrm{CO}_{2}$ capturing capacities after operating up to ten cycles are shown on Fig. 7. From the experimental results, it can be concluded that the synthesized cerium product has not only a high adsorption capacity for $\mathrm{CO}_{2}$ capture at room temperature under a high pressure condition, but also the good regenerating performance at room temperature under atmospheric pressure. Therefore, mesoporous ceria compound may be available a high efficient and energy-saving adsorbent for $\mathrm{CO}_{2}$ PSA-capture from flue gas under a high pressure.

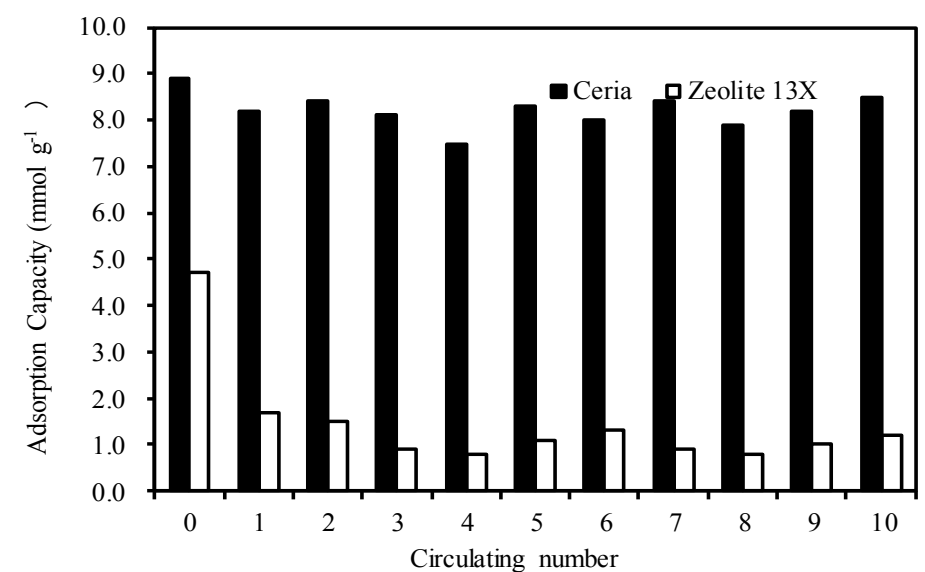

Fig. 7. $\mathrm{CO}_{2}$ adsorption- desorption circulating tests at $298 \mathrm{~K}$ in the pressure range of $0.1 \mathrm{MPa} \sim 1.0 \mathrm{MPa}$.

\section{Conclusion}

A high performance mesoporous cerium compound as the adsorbent for $\mathrm{CO}_{2}$ capture has been successfully synthesized based on sol-gel method without template. The morphologic features and the porous characteristics of the synthesized cerium compound products are significantly affected by the concentration of alkaline solution added to the hydrolyzed $\mathrm{Ce}\left(\mathrm{NO}_{3}\right)_{3}$ to obtain $\mathrm{Ce}(\mathrm{OH})_{3}$. Although the surface area of the synthesized cerium compound product (even though the largest one was up to $206 \mathrm{~m}^{2} \mathrm{~g}^{-1}$ ) is smaller than that of the commercially available zeolite $13 \mathrm{X}$ and activated carbon, the synthesized products have higher adsorption performance than the commercial adsorbents especially under higher pressure. Because of its excellent desorption performance at room temperature and under atmospheric pressure, the synthesized mesoporous cerium compound is promising for $\mathrm{CO}_{2}$ capture with the pressure swing adsorption (PSA) process as a high performance adsorbent.

\section{References}

1. W. Chaikittisilp, H. Kim, C.W. Jones, Energy Fuels, 25 (2011)

2. J.Yu, Y.Le, B. Cheng, RSC Adv. 2 (2012)

3. R.J. Gorte, AIChe J. 56 (2010)

4. Y. Kamimura, M. Shimomura, A. Endo, J. Colloid Interface Sci. 436 (2014) 